Supplement of Biogeosciences, 12, 3623-3638, 2015

http://www.biogeosciences.net/12/3623/2015/

doi:10.5194/bg-12-3623-2015-supplement

(C) Author(s) 2015. CC Attribution 3.0 License.

(c) (i)

Supplement of

\title{
Understanding emissions of ammonia from buildings and the application of fertilizers: an example from Poland
}

M. Werner et al.

Correspondence to: M. Werner (m.werner@worc.ac.uk)

The copyright of individual parts of the supplement might differ from the CC-BY 3.0 licence. 
Table S1. The definitions of error measures used in the study.

\begin{tabular}{|c|c|c|}
\hline Name & Equation & Value \\
\hline Mean Error & $M E=\frac{1}{N} \sum_{i=1}^{N}\left(M_{i}-O_{i}\right)$ & $\begin{array}{l}-\infty \text { to }+\infty \\
\text { perfect score: } 0\end{array}$ \\
\hline $\begin{array}{l}\text { Mean } \\
\text { Absolute } \\
\text { Error }\end{array}$ & $M A E=\frac{1}{N} \sum_{i=1}^{N}\left|M_{i}-O_{i}\right|$ & $\begin{array}{r}0 \text { to }+\infty \\
\text { perfect score: } 0\end{array}$ \\
\hline $\begin{array}{l}\text { Pearson } \\
\text { Correlation } \\
\text { Coefficient }\end{array}$ & $R=\frac{\sum_{i=1}^{N}\left(M_{i}-\bar{M}\right)\left(O_{i}-\bar{O}\right)}{\left\{\sum_{i=1}^{N}\left(M_{i}-\bar{M}\right)^{2} \sum_{i=1}^{N}\left(O_{i}-\bar{O}\right)^{2}\right\}^{\frac{1}{2}}}$ & $\begin{array}{l}-1 \text { to } 1 \\
\text { perfect score: } 1\end{array}$ \\
\hline $\begin{array}{l}\text { Index of } \\
\text { Agreement }\end{array}$ & $I O A=\frac{N \times \sum_{i=1}^{N}\left(M_{i}-O_{i}\right)^{2}}{\sum_{i=1}^{N}\left(\left|M_{i}-\bar{O}\right|+\left|O_{i}-\bar{O}\right|\right)^{2}}$ & $\begin{array}{c}0 \text { to } 1 \\
\text { perfect score: } 1\end{array}$ \\
\hline
\end{tabular}

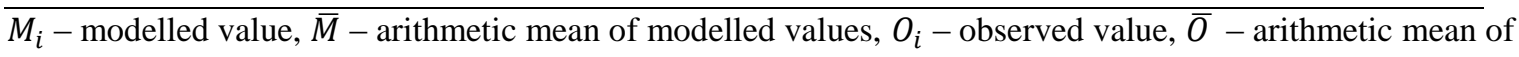
observed values, $N$ - number of pairs (model, observation). 